Check for updates

Cite this: Chem. Sci., 2019, 10, 7358

๑ All publication charges for this article have been paid for by the Royal Society of Chemistry

\title{
Stereoselective total synthesis of parthenolides indicates target selectivity for tubulin carboxypeptidase activity $\dagger^{\dagger}$
}

\author{
Robert R. A. Freund, (DD a Philipp Gobrecht, ${ }^{\mathrm{b}}$ Zhigang Rao, ${ }^{\mathrm{c}}$ Jana Gerstmeier, ${ }^{\mathrm{c}}$ \\ Robin Schlosser, ${ }^{a}$ Helmar Görls, ${ }^{d}$ Oliver Werz, ${ }^{c}$ Dietmar Fischer (iD) ${ }^{b}$ \\ and Hans-Dieter Arndt (D) *a
}

The 2-(silyloxymethyl)allylboration of aldehydes was established to enable stereoselective access to $\alpha$ (exo)-methylene $\gamma$-butyrolactones under mild conditions. Acid-labile functionality and chiral carbonyl compounds are tolerated. Excellent asymmetric induction was observed for $\beta, \beta^{\prime}$-disubstituted $\alpha, \beta$-epoxy aldehydes. These findings led to the enantioselective total synthesis of the sesquiterpene natural product $(-)$-parthenolide, its unnatural (+)-enantiomer, and diastereoisomers. Among all the isomers tested in cell culture, only (-)-parthenolide showed potent inhibition of microtubule detyrosination in living cells, confirming its exquisite selectivity on tubulin carboxypeptidase activity. On the other hand, the antiinflammatory activity of the parthenolides was weaker and less selective with regard to compound stereochemistry.

Received 25th March 2019

Accepted 14th June 2019

DOI: $10.1039 /$ c9sc01473j

rsc.li/chemical-science

activation and regulation are still difficult to study. Tool compounds with specific activity on TCP would have significant importance for medical research and potentially drug development. In this regard, for enabling thorough studies of parthenolide, a fully stereocontrolled de novo synthesis of the natural product was sought that is based on exchangeable building blocks and provides liberal access to stereoisomers for studying target selectivity.

Previously reported syntheses of parthenolide did not allow a comprehensive study (Scheme 1). Chen and co-workers employed the linear epoxy aldehyde $\mathbf{2 a , b}$ and an intramolecular, non-diastereoselective Nozaki-Hiyama-Kishi allylation (a), followed by $(Z \rightarrow E)$ isomerization of the internal alkene. ${ }^{12}$ The lactone was obtained after aminolysis of the nitrile and refunctionalization (d). A second synthesis featured an aldol addition of chiral camphorsultam derivative $\mathbf{4 a , b}$ to $\alpha, \beta$ unsaturated aldehyde 3 (a), leading to a separable product mixture. ${ }^{13}$ Refunctionalization, intramolecular alkylation (b)

${ }^{a}$ Institut für Organische Chemie und Makromolekulare Chemie, Friedrich-Schiller-Universität, Humboldtstr. 10, 07743 Jena, Germany. E-mail: hd.arndt@uni-jena.de

${ }^{b}$ Lehrstuhl für Zellphysiologie, Ruhr-Universität Bochum, Universitätsstr. 150, ND/4, 44780 Bochum, Germany

'Institut für Pharmazie, Friedrich-Schiller-Universität, Philosophenweg 14, 07743 Jena, Germany

${ }^{d}$ Institut für Anorganische Chemie und Analytische Chemie, Friedrich-SchillerUniversität, Humboldtstr. 8, 07743 Jena, Germany

$\dagger$ Electronic supplementary information (ESI) available: Syntheses of starting materials. Experimental procedures, analytical data for all new compounds. Cell and macrophage experiment methods and data. NMR based structure elucidation of compound $16 \mathrm{f}$ (PDF). X-ray of compound ( \pm )-9 (CIF). CCDC 1902988. For ESI and crystallographic data in CIF or other electronic format see DOI: $10.1039 / \mathrm{c} 9 \mathrm{sc} 01473 \mathrm{j}$ hydroxyl-directed epoxidation and oxidative lactonization (d) gave 1. Recently, Liu and co-workers reported a racemic parthenolide synthesis ${ }^{\mathbf{1 4}}$ based on Still's ring enlarging oxy-Cope rearrangement of 1,5-diene $( \pm)-5(\mathrm{~b})$, followed by $(Z \rightarrow E)$ isomerization of an internal alkene. ${ }^{15} \alpha$-Alkylation of the resulting ketone with ethyl bromoacetate $(6, c)$, reduction, epoxidation, oxidative lactonization (d) and $\alpha$-methylenation ( 7 ) completed the synthesis. Additionally, syntheses of parthenolide's natural precursor costunolide (8) were described, ${ }^{\mathbf{1 6}}$ from which parthenolide is available. ${ }^{17}$ Various syntheses leading to diastereomers of the natural product have been reported as well. ${ }^{12,18}$ 


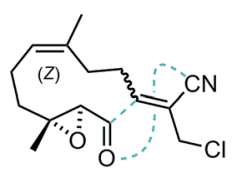

$2 a, b$ a $\Uparrow$ [ref. 11]

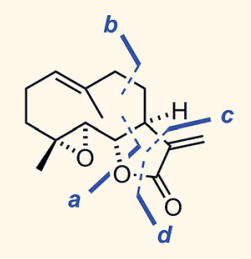

(-)-parthenolide (1)

[ref. 16]
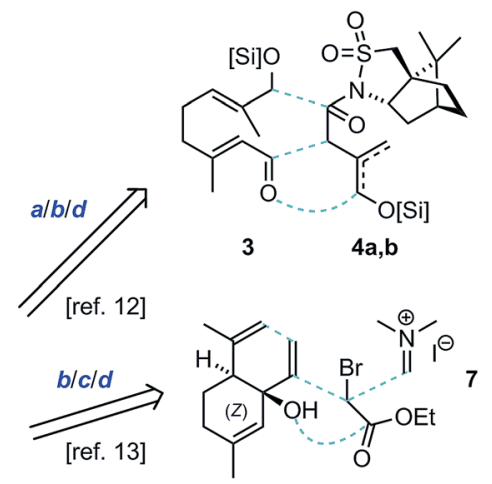

$( \pm)-5$

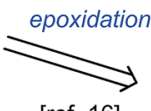

this work $\Downarrow \begin{aligned} & \text { sulfone allylation (b) } \\ & \text { oxidative lactonization (d) } \\ & \text { epoxide inversion }\end{aligned}$

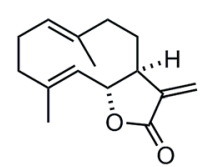

(+)-costunolide (8)

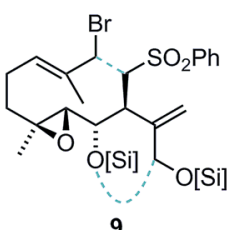
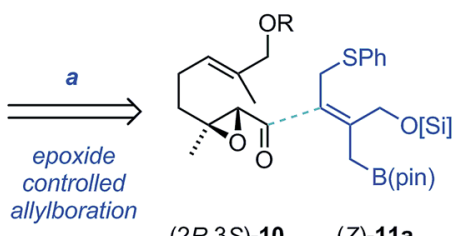

(2R,3S)-10

Scheme 1 Previous targeted syntheses of parthenolides and stereodivergent synthesis planning of this work, revealing a reactive 2 -(silyloxy-methyl)allylboronate. [Si] $=\mathrm{SiR}^{1} \mathrm{R}^{2} \mathrm{R}^{3}$.

In order to realize a modular, enantioselective, and stereocontrolled synthesis, we envisioned to use an intramolecular sulfone allylation to close the ten-membered ring (Scheme 1, bottom). ${ }^{13,19}$ Precursor 9 already contains the epoxide motif and is geared for late stage oxidative lactonization to form the reactive $\alpha \mathrm{M} \gamma \mathrm{B} .{ }^{17,18 b}$ Several indirect as well as direct syntheses of $\alpha \mathrm{M} \gamma \mathrm{Bs}$ have been reported. ${ }^{\mathbf{1}, \boldsymbol{b}}$ Among them, allylboration methods offered predictable high stereoselectivity, ${ }^{\mathbf{1 b}, \mathbf{2 0}}$ which has been a major challenge in previous parthenolide syntheses. Accordingly, diastereoselective allylboration directed by the epoxide's and the boronate's stereochemistry, simplifies sulfone 2 to the chiral $\alpha, \beta$-epoxy aldehyde 10 and the novel 2(silyloxymethyl)allylboronate $(Z)$-11a. The epoxide group was expected to provide 1,2-asymmetric induction, ${ }^{21}$ but its level and its sense (Felkin or anti-Felkin) were not clear for these unknown allylboronates at the onset of our studies. However, by using either enantiomer of the epoxy aldehyde, and additionally epoxide inversion, any desired stereoisomer should be obtained (see also Scheme 5 below).

Moreover, by design, the allylboronate 11a should operate as a "linchpin" reagent for $\alpha \mathrm{M} \gamma \mathrm{B}$ synthesis in general. Being electron rich, it was expected to display intrinsically high allylation rates and to reliably install the trans configuration of the $\alpha \mathrm{M} \gamma \mathrm{B}(\rightarrow \mathbf{1}){ }^{20}$ Hence, these allylboronates should allow allylboration-based $\alpha \mathrm{M} \gamma \mathrm{B}$ synthesis from acid labile carbonyl

compounds such as aldehyde 10. These substrates are incomepatible with 2-(alkoxycarbonyl)allylboration reagents that demand activation by either Lewis/Brønsted acids or elevated temperature. ${ }^{\mathbf{2 0 2} 2}$ Hence, a significant scope and broader applicability were expected for these new allyl boronates.

\section{Results and discussion}

To explore the scope and feasibility of this approach and the utility of the reagents envisioned, we prepared the pseudo-trans configured (Z)-2-(silyloxymethyl)allylboronates (Z)-11a-c (Scheme 2) starting from 2-butyne-1,4-diol (12) by using a combination of syn-selective hydrostannylation ${ }^{23}$ and regioselective functionalization to obtain the versatile alkenyl halide 15 (50\% yield, 6 steps). Introduction of a desired side chain by nucleophilic substitution, followed by a Negishi coupling with Knochel's $\mathrm{IZnCH}_{2} \mathrm{~B}$ (pin) reagent ${ }^{24}$ allowed then the stereo- and regioselective preparation of the stable 2-(silyloxymethyl)allylboronates (Z)-11a-c in good yields (Scheme 2).

Next, reagents $(Z)-\mathbf{1 1 a}-\mathbf{c}$ were investigated for allylboration of achiral aldehydes and chiral $\alpha, \beta$-epoxy carbonyl compounds (for their preparation see the ESI $\dagger$ ), where focus was placed on acidlabile features (Scheme 3). Gratifyingly, allylboration proceeded cleanly between 0 and $25{ }^{\circ} \mathrm{C}$ without the addition of external acidic activators. In fact, buffering by using solid $\mathrm{NaHCO}_{3}$ was found essential to obtain reproducible yields, especially for more labile aldehydes. Optimized conditions for the reaction of boronates $(Z)$-11a or $(Z)-11 c$ with aryl $(\rightarrow \mathbf{1 6 a}, \mathbf{b})$, alkyl $(\rightarrow \mathbf{1 6}$ c) as well as a $\beta$-alkoxy aldehydes $(\rightarrow \mathbf{1 6 d})$ gave the homoallylic

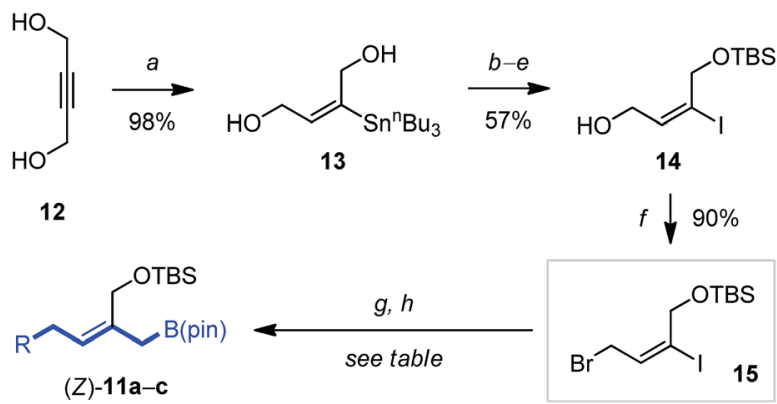

\begin{tabular}{|lll|}
\hline Boronate & $\mathrm{R}$ (isol. yield step g) & Isol. yield step $\mathrm{h}$ \\
\hline (Z)-11a & PhS- (96\%) & $40-66 \%$ \\
$(Z)-11 \mathrm{~b}$ & Methallyl- (94\%) & $54 \%$ \\
$(Z)-11 \mathrm{c}$ & Allyl- (96\%) & $50 \%$ \\
\hline
\end{tabular}

Scheme 2 (Z)-2-(Silyloxymethyl)allylboronate synthesis. The pseudotrans configured allylboronate (bold) has nominally $(Z)$-configuration. Reagents and conditions: (a) $\left[\mathrm{Pd}(\mathrm{PPh})_{3}\right]_{4}(1 \mathrm{~mol} \%),{ }^{n} \mathrm{Bu}_{3} \mathrm{SnH}, \mathrm{THF}, 0{ }^{\circ} \mathrm{C}$, $2 \mathrm{~h}, 98 \%$; (b) $\mathrm{Ac}_{2} \mathrm{O}, \mathrm{Et}_{3} \mathrm{~N}, \mathrm{CH}_{2} \mathrm{Cl}_{2}, 5^{\circ} \mathrm{C}, 24 \mathrm{~h}, 68 \%$; (c) $\mathrm{I}_{2}, \mathrm{CH}_{2} \mathrm{Cl}_{2},-78{ }^{\circ} \mathrm{C}$, $3 \mathrm{~h}, 92 \%$; (d) $\mathrm{TBSCl}$, imidazole, $0^{\circ} \mathrm{C}$ to $\mathrm{rt}, 3 \mathrm{~h}$; (e) $\mathrm{K}_{2} \mathrm{CO}_{3}, \mathrm{MeOH}, 0^{\circ} \mathrm{C}$ to rt, 2 h, 83\% (2 steps); (f) NBS, $\mathrm{PPh}_{3}, \mathrm{CH}_{2} \mathrm{Cl}_{2},-40{ }^{\circ} \mathrm{C}, 3 \mathrm{~h}, 90 \%$; (g) $(\rightarrow 11 \mathrm{a}): \mathrm{PhSH}, \mathrm{NaOMe}, \mathrm{MeOH},-20{ }^{\circ} \mathrm{C}, 10 \mathrm{~min}$, then $15,-20$ to $0{ }^{\circ} \mathrm{C}$, 3 h, 96\%; ( $\rightarrow 11 \mathrm{~b})$ : MethallylMgBr, THF, $-40{ }^{\circ} \mathrm{C}, 2 \mathrm{~h}, 94 \%$; $(\rightarrow 11 \mathrm{c})$ : AllylMgBr, THF, $-40{ }^{\circ} \mathrm{C}, 2 \mathrm{~h}, 96 \%$; (h) $\mathrm{IZnCH}_{2} \mathrm{~B}(\mathrm{pin}),\left[\mathrm{Pd}(\mathrm{PPh})_{3}\right]_{4}$ (10 mol\%), THF, $60^{\circ} \mathrm{C}, 2 \mathrm{~h}$. 


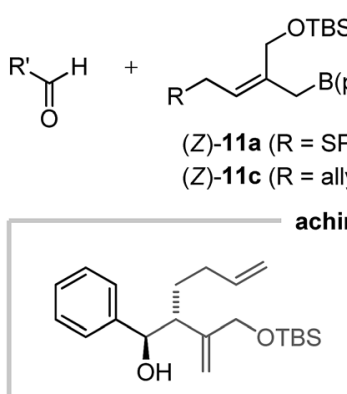

$( \pm)-16 a: 81 \%,>99: 1 d r(a)$

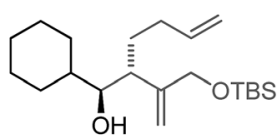

(士)-16c: $86 \%,>99: 1 d r(a)$

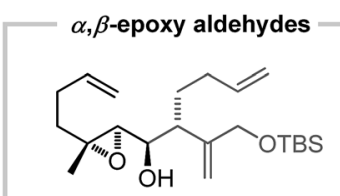

(土)-16f: $82 \%, 7: 1 d r(a)$ $92 \%, 18: 1 d r(b)$

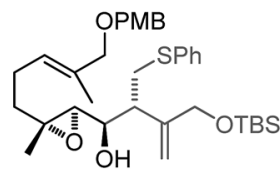

16g: $94 \%, 19: 1 d r(b)$

$\alpha, \beta$-epoxy ketone

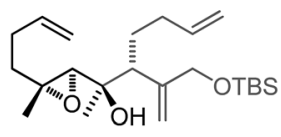

16j: $0 \%$

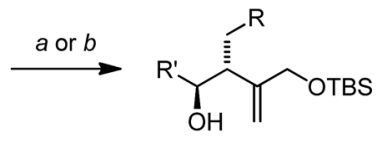

$16 a-j$

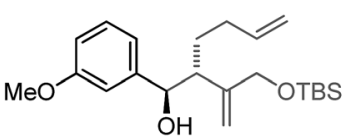

(士)-16b: $84 \%,>99: 1 d r(a)$

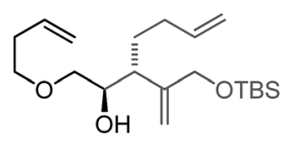

( \pm -16d: 70\%, >99:1 dr (a)

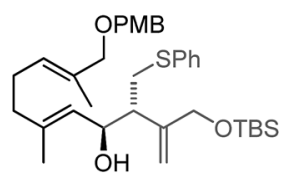

$( \pm)-16 e: 94 \%, 19: 1 d r(b)$

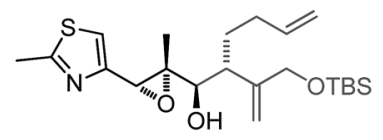

$( \pm)-16 h: 75 \%, 1.1: 1 d r(a)$ $87 \%, 1.6: 1 d r(b)$

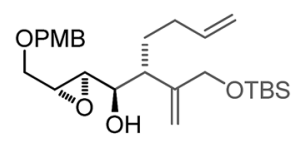

( \pm )-16i: $70 \%, 1.2: 1 d r(a)$ $84 \%, 1.5: 1 d r(b)$
Scheme 3 (Z)-2-(Silyloxymethyl)allylboration. Conditions: (Z)-11 (1.0 equiv.), aldehyde (1.1-1.5 equiv.), $\mathrm{NaHCO}_{3}$ (0.05 equiv.), $\mathrm{Et}_{2} \mathrm{O}(0.2 \mathrm{M})$; (a) 0 to $25{ }^{\circ} \mathrm{C}, 24 \mathrm{~h}$; (b) $0-5{ }^{\circ} \mathrm{C}, 48 \mathrm{~h}$. Combined yields are given, $\mathrm{dr}$ refers to Felkin vs. anti-Felkin product, major isomer depicted. dr was determined by GC-MS, HPLC, or NMR

alcohol products in very good yield and excellent diastereoselectivity (Scheme 3). An $\alpha, \beta$-unsaturated aldehyde $(\rightarrow \mathbf{1 6 e}$ ) was equally effective (19: $1 \mathrm{dr}$ ). $\alpha, \beta$-Epoxy aldehyde substrates were investigated next. All aldehydes with $\alpha, \beta, \beta^{\prime}$ epoxide substitution patterns $(\rightarrow \mathbf{1 6 f}, \mathbf{g})$ were transformed with excellent yield and $>18: 1 \mathrm{dr}$. In contrast, for the reactions of an $\alpha, \alpha^{\prime}, \beta$ trisubstituted $(\rightarrow \mathbf{1 6 h})$ or an $\alpha, \beta$ disubstituted epoxy aldehyde $(\rightarrow \mathbf{1 6 i})$ negligible 1,2-asymmetric induction was observed.

Substitution at the epoxide's $\beta^{\prime}$ position seems to be key for diastereocontrol during allylboration. Notably, an $\alpha, \beta$-epoxy ketone $(\mathbf{1 6 j})$ remained unreactive. The relative stereochemistry of alcohol $\mathbf{1 6 f}$ was assigned by NOESY NMR of a cyclized derivative (see the ESI $\dagger$ ) which indicated strict Felkin control. ${ }^{\mathbf{2 1 c}}$
Hence, the excellent stereocontrol of these novel allylboronates could be exploited for the synthesis of 4,5-dia-parthenolide (22). By using a late stage epoxide inversion, the natural parthenolide (1) could be synthesized.

Consequently, the allylboration product $(+)-\mathbf{1 6 g}(92 \%$ ee) was cleanly protected with a TBS group $(\rightarrow(+)-17$, Scheme 4$)$ at low temperature, to suppress (Lewis-) acid induced epimerization. Chemoselective oxidation of the thioether gave the sulfone $(+)-18$. The PMB ether of $\mathbf{1 8}$ was cleaved by treatment with DDQ in a quaternary aqueous solvent mixture, which drastically reduced the reaction time and reagent amount needed, compared to common biphasic mixtures. After work up with $\mathrm{NaBH}_{4}$ (to reduce some enal byproduct formed), the allylic alcohol obtained was transformed into the allylic bromide (-)-9 by mesylation and in situ substitution with $\operatorname{LiBr}(82 \%$ over 2 steps). Structure and relative configuration of $( \pm)-\mathbf{9}$ were verified by single-crystal X-ray analysis (see the ESI $\dagger$ ). Closure of the tenmembered ring was then achieved by intramolecular substitution. Optimized conditions featured addition of the sulfone 9 to excess KHMDS at $0{ }^{\circ} \mathrm{C}$ in THF at a final dilution of $4 \mathrm{mM}$, giving rise to the separable sulfone diastereomers 19a,b. The yield of this challenging transformation was somewhat scale dependent. Under optimized conditions the reaction could be performed on viable scale $(100 \mathrm{mg})$ in high yield $(80 \%)$. Next, the sulfone diastereomers 19a,b were reductively desulfonylated with sodium amalgam,${ }^{25}$ providing epoxy germacrane $(+)-20$ in good yield (70\%). Other reductive conditions, such as $\mathrm{Mg} /$ $\mathrm{MeOH}^{13}$ or $[\mathrm{Na}(15-\mathrm{c}-5)] \mathrm{e} / \mathrm{THF},{ }^{26}$ led to the formation of inseparable side products or overreduction.

Twofold $O$-TBS deprotection (Scheme 5) of germacrane 20 then gave the labile epoxy diol $(+)-21$ that was immediately

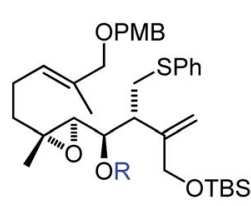

$(+)-\mathbf{1 6 g}(\mathrm{R}=\mathrm{H})$
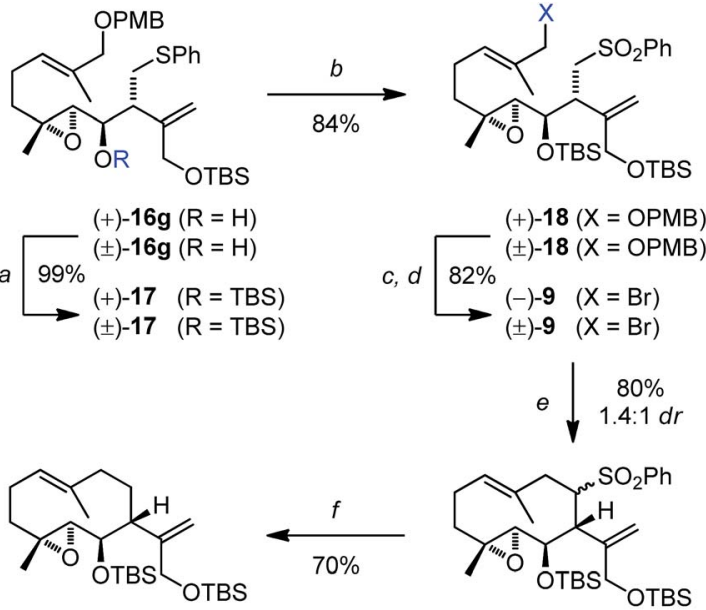

$(+)-20$

$( \pm)-20$ $\pm)-17 \quad(R=T B S)$

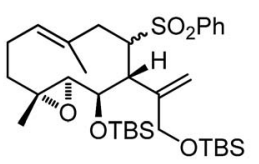

$19 a, b$

$( \pm)-19 a, b$
Scheme 4 Stereoselective synthesis of germacranoide 9. Reagents and conditions: (a) TBSOTf, 2,6-lutidine, $\mathrm{MeCN},-30{ }^{\circ} \mathrm{C}, 99 \%$; (b) $\left(\mathrm{NH}_{4}\right)_{6} \mathrm{Mo}_{7} \mathrm{O}_{24} \cdot 4 \mathrm{H}_{2} \mathrm{O}$, aq. $\mathrm{H}_{2} \mathrm{O}_{2},{ }^{t} \mathrm{BuOH} /$ pyridine $(4: 1), 0{ }^{\circ} \mathrm{C}$ to rt, $16 \mathrm{~h}$, $82 \%$; (c) (i) $\mathrm{DDQ}, \mathrm{CH}_{2} \mathrm{Cl}_{2} /{ }^{t} \mathrm{BuOH} / \mathrm{MeCN} / \mathrm{pH} 7$ buffer $(9: 1: 1: 1), 0{ }^{\circ} \mathrm{C}$, $2 \mathrm{~h}$, (ii) $\mathrm{NaBH}_{4}, \mathrm{MeOH} / \mathrm{CH}_{2} \mathrm{Cl}_{2}$ (5:2), $0{ }^{\circ} \mathrm{C}, 1 \mathrm{~h}, 92 \%$; (d) $\mathrm{MsCl}, \mathrm{Et}_{3} \mathrm{~N}$, THF, $0{ }^{\circ} \mathrm{C}, 2 \mathrm{~h}$, then $\mathrm{LiBr}, 0{ }^{\circ} \mathrm{C}, 1.5 \mathrm{~h}, 89 \%$; (e) KHMDS, THF $[4 \mathrm{mM}], 0^{\circ} \mathrm{C}$, $30 \mathrm{~min}, 80 \%, 1.4: 1 \mathrm{dr}$; (f) Na/Hg 5 : 95, MeOH/THF (5 : 1), rt, 1.5 h, 70\%. 


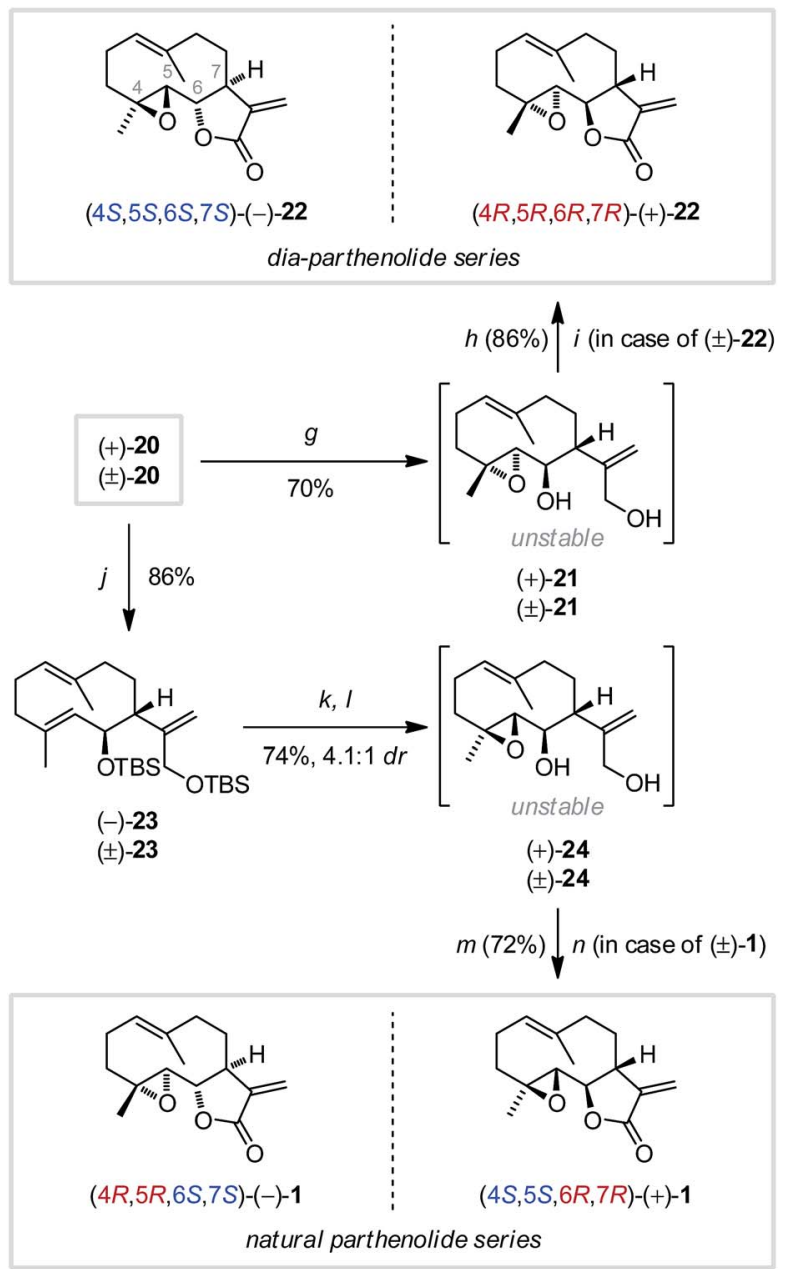

Scheme 5 Completion of parthenolides syntheses. Reagents and conditions: (g) TBAF. $3 \mathrm{H}_{2} \mathrm{O}$, THF, rt, $18 \mathrm{~h}, 70 \%$; (h) TEMPO (30 mol\%), $\mathrm{Phl}(\mathrm{OAC})_{2}, \mathrm{CH}_{2} \mathrm{Cl}_{2}, \mathrm{rt}, 18 \mathrm{~h}, 86 \%$; (i) chiral HPLC (72\%); (j) $\mathrm{WCl}_{6}+{ }^{n} \mathrm{BuLi}$ (1: 3), THF, -78 to $15{ }^{\circ} \mathrm{C}, 1.5 \mathrm{~h}$, then 9,0 to $10{ }^{\circ} \mathrm{C}, 18 \mathrm{~h}, 86 \%$; (k) TBAF $3 \mathrm{H}_{2} \mathrm{O}$, THF, rt, $18 \mathrm{~h}, 93 \%$; (l) $\mathrm{Ti}\left(\mathrm{O}^{\mathrm{i}} \mathrm{Pr}\right)_{4}(20 \mathrm{~mol} \%)$, L-(+)-DIPT (25 mol\%), ${ }^{t} \mathrm{BuOOH}, 4 \AA \mathrm{mol}$. sieves, $\mathrm{CH}_{2} \mathrm{Cl}_{2},-40$ to $-20{ }^{\circ} \mathrm{C}, 18 \mathrm{~h}, 80 \%$, 4.1 : $1 \mathrm{dr}$; (m) TEMPO (30 mol\%), PhI(OAc) $)_{2} \mathrm{CH}_{2} \mathrm{Cl}_{2}, \mathrm{rt}, 18 \mathrm{~h}, 67 \%$; (n) chiral HPLC (66\%).

transformed into the $\alpha \mathrm{M} \gamma \mathrm{B}$ by using $\mathrm{PhI}(\mathrm{OAc})_{2}$ and substoichiometric TEMPO,${ }^{17}$ providing the $(4 R, 5 R, 6 R, 7 R)$-parthenolide diastereomer $(+)$-22, also termed 4,5-dia-parthenolide, ${ }^{18 b}$ in good yield. The enantiomeric $(4 S, 5 S, 6 S, 7 S)$-(-)-isomer was obtained from racemic $( \pm)-22$ by using chiral HPLC separation. The challenging deoxygenation of epoxide (+)-20 by low valent tungsten chlorides ${ }^{18 a, 27}$ was then investigated. Specific stoichiometry $\left.\left(\mathrm{WCl}_{6}\right)^{n} \mathrm{BuLi} 1: 3\right)$ and temperature control, both during the formation of the reagent $\left(-78\right.$ to $\left.15^{\circ} \mathrm{C}\right)$ and for the transformation of the epoxide $\left(0\right.$ to $\left.10^{\circ} \mathrm{C}\right)$, delivered the isomerically pure, acid sensitive germacrane (-)-23 in $86 \%$ yield. Interestingly, the more Lewis acidic $\mathrm{WCl}_{6} /{ }^{n} \mathrm{BuLi} 1: 2$ reagent induced transannular cyclization, ${ }^{18 a, 28}$ whereas a reagent formed from $\mathrm{WCl}_{6} /{ }^{n} \mathrm{BuLi}$ in $1: 4$ stoichiometry remained unreactive. Experiments employing a Rh-carbenoid-mediated deoxygenation method $^{29}$ led to decomposition.
Epoxidation with opposite stereochemistry was achieved after twofold TBS group removal (TBAF) and directed Sharpless epoxidation (4.1:1 dr, 74\% yield), unfortunately without significant influence of the ligand's stereochemistry on the reaction stereoselectivity, in line with earlier reports for similar transformations. ${ }^{14,18 b}$ The labile epoxy diol (-)-24 thus obtained was oxidized to the $\alpha \mathrm{M} \gamma \mathrm{B}$ to provide (+)-parthenolide $[(4 S, 5 S, 6 R, 7 R)-1]$ in $72 \%$ yield. Alternatively, chiral HPLC separation of racemic $( \pm)-\mathbf{1}$ provided both enantiomers of natural parthenolide. The (-)-form $[(4 R, 5 R, 6 S, 7 S)-1]$ was identical with an authentic sample.

Parthenolide has been associated with a variety of biological activities, which may be specific or unspecific, as $\alpha \mathrm{M} \gamma \mathrm{Bs}$ are fairly reactive electrophiles. ${ }^{2 a, 30}$ A hallmark of TCP activity, which was of special interest, is the modulation of tyrosinated tubulin in living cells. ${ }^{8 d, 31}$ As a relevant model, we primarily chose to test how parthenolide's stereochemistry influences microtubule detyrosination in axonal growth cones of primary sensory neurons. It was previously shown that inhibition of microtubules detyrosination by parthenolide in a low concentration range of $0.5-5 \mathrm{nM}$ markedly promotes microtubule dynamics and axon growth of cultured sensory neurons, thereby accelerating axonal growth. ${ }^{8}$ It, therefore, mimics the beneficial effects of constitutively active glycogen synthase kinase 3 (GSK3) on nerve regeneration by modulating microtubule detyrosination via MAP1B activation. ${ }^{8 b}$ However, parthenolide loses its beneficial effect on axon growth in vitro again at higher concentrations and even reduces axon growth at very high concentrations. ${ }^{8}$ This is because a strong inhibition of detyrosination rather destabilizes microtubules and subsequently axon extension. ${ }^{8}$ Previous work with costunolide and parthenolide indicated that parthenolide's Michael acceptor and the epoxide group are both crucial for the activity observed. ${ }^{8 a}$

In order to gain a deeper understanding of the target selectivity, we compared natural parthenolide derived from feverfew to synthetic (-)-1, (+)-1, (-)-22, and (+)-22 in mouse primary cell culture (Fig. 1). Both natural parthenolide and synthetic (-)-1 inhibited detyrosination of microtubules in axonal growth cones at $1 \mathrm{nM}$ to a similar degree, while (+)-1 showed a smaller but still considerable effect. Isomers (-)-22 and (+)-22 indicated no significant activity, also not at higher concentration (not shown). To corroborate this finding, we functionally tested the compounds regarding their concentration-dependent activity on axon growth (Fig. 2). Again, both natural and synthetic parthenolide [(-)-1] almost equally promoted axon growth of cultured sensory neurons at $0.5 \mathrm{nM}$ and to a stronger extent at $1 \mathrm{nM}$, when the lengths of regenerated axons were evaluated after 48 hours in culture (Fig. $2 \mathrm{~A}$ and B). At $5 \mathrm{nM}$, the beneficial effects of native and synthetic parthenolide [(-)-1] were almost abolished, and $50 \mathrm{nM}$ even reduced axon growth, thereby demonstrating a very similar functional profile over different concentrations. In contrast to those compounds, the enantiomer $(+)-\mathbf{1}$ showed a small, but statistically significant effect only at $1 \mathrm{nM}$. Interestingly, also at $50 \mathrm{nM}$, the enantiomer (+)-1 did not reduce axon regeneration. Isomers $(-)-22$ and (+)-22 showed no significant increase or decrease in axon growth in 


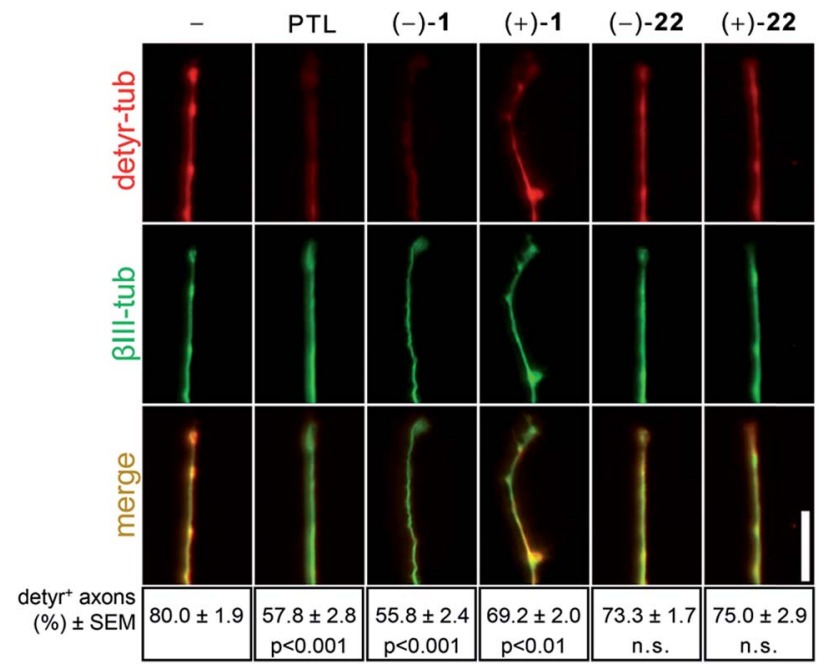

Fig. 1 Detyrosination of tubulin in axonal growth. Top: Representative images of cultured sensory axon tips treated either with DMSO (-), plant-derived parthenolide ( $\mathrm{PTL}, \mathrm{C}=1 \mathrm{nM})$, and synthetic parthenolides $(-)-1,(+)-1,(-)-22$, and $(+)-22(c=1 \mathrm{nM}$ each). Axons were immunostained for detyrosinated tubulin (detyr-tub, red) and $\beta I I I-$ tubulin ( $\beta$ III-tub, green, see ESI $\uparrow$ ). Scale bar: $20 \mu \mathrm{m}$. Bottom: Quantification of axons tips from cultured sensory neuron positive for detyrosinated tubulin. Axon tips were determined to be positive with a gray value above 30 after background subtraction. Data represent means \pm SEM of two independent experiments. Statistics: Significance very high: $p \leq 0.001$; considerable: $p \leq 0.01$; n.s.: not significant, SEM standard error mean.

the tested concentration range, which is in line with the results from detyrosination experiments.

In order to study the selectivity of parthenolides against TCP activity as a putative target compared to its reported antiinflammatory activity, ${ }^{32}$ we investigated the anti-inflammatory features of natural parthenolide along with the synthetic stereoisomers (-)-1, (+)-1, (-)-22, and (+)-22 in human monocyte-derived macrophages during lipopolysaccharide (LPS)/interferone (INF)- $\gamma$-induced $48 \mathrm{~h}$ polarization into the M1 phenotype. Parthenolide, at low micromolar concentrations, inhibits IK-B kinase ${ }^{5 b}$ and related expression of cyclooxygenase (COX)-2 and tumor necrosis factor (TNF)- $\alpha$ in LPS-activated macrophages. ${ }^{33}$ MTT assays revealed some but no significant loss of cell viability by the compounds at $10 \mu \mathrm{M}$, while at $30 \mu \mathrm{M}$ all parthenolides displayed significant cytotoxicity (Fig. 3A). At $10 \mu \mathrm{M}$, PTL suppressed COX-2 expression and TNF- $\alpha$ release, which was more pronounced for synthetic $(-)-\mathbf{1}$ and $(+)-\mathbf{1}$, with $(+)-\mathbf{1}$ being little superior over (-)-1 (Fig. 3B and C). Of interest, isomers $(-)-22$ and $(+)-22(10 \mu \mathrm{M}$, each) were equally bioactive, and (-)-22 turned out to be the most potent stereoisomer in suppressing COX-2 (Fig. 3B and C).

In combination, these data show that natural (-)-parthenolide as well as the stereoisomers are not significantly cytotoxic for macrophages up to $10 \mu \mathrm{M}$, but loss of cell viability is evident at $30 \mu \mathrm{M}$. These data compare favorably with data obtained earlier for the natural product on neuronal cells. ${ }^{8 b}$ Antiinflammatory activity (i.e., suppression of COX-2 and TNF- $\alpha)^{33}$ could be confirmed, but somewhat unexpectedly, no marked
A
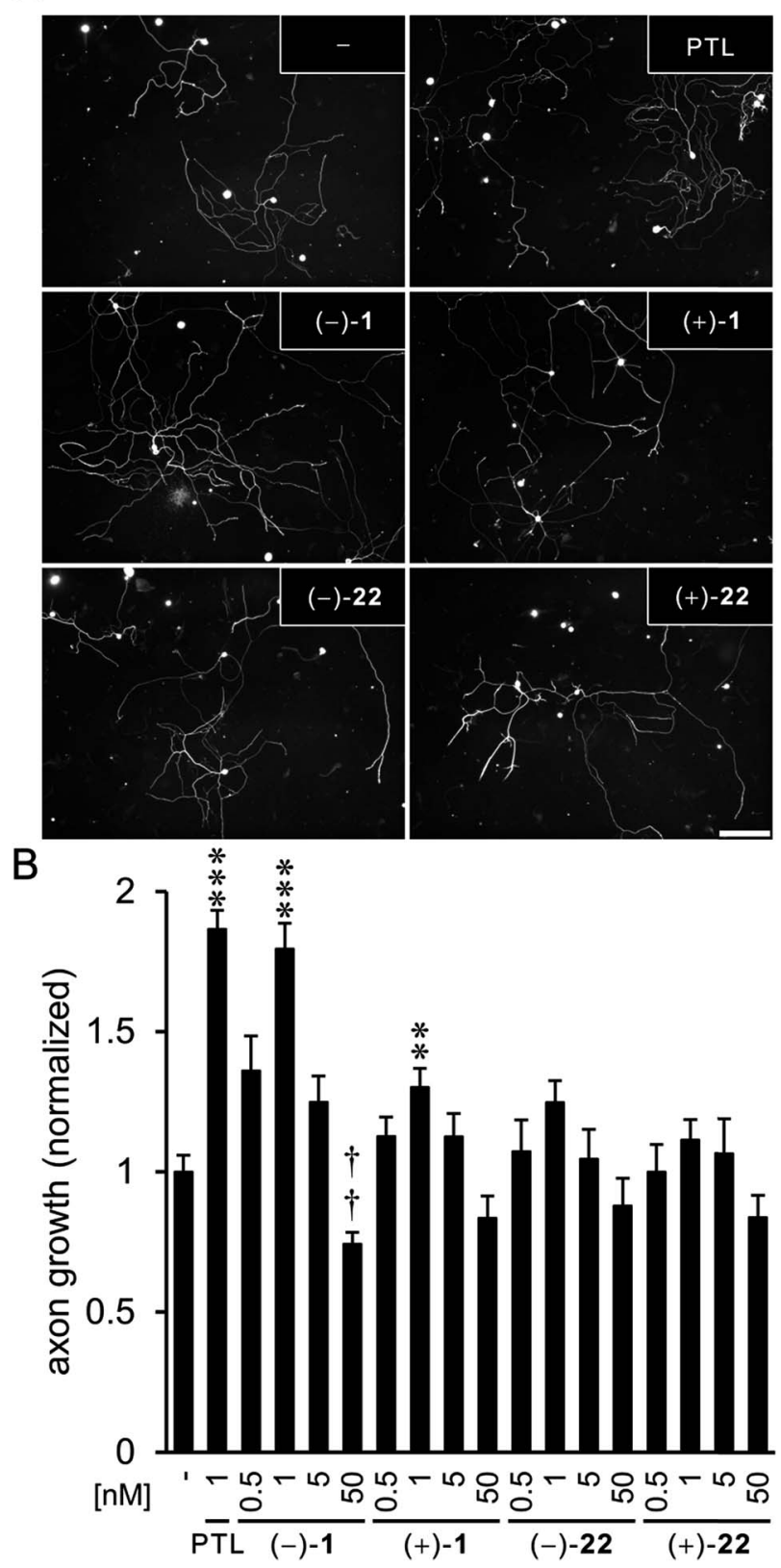

Fig. 2 Synthetic parthenolide promotes axon growth of adult sensory neurons. (A) Representative pictures of dissociated sensory DRG neurons treated with DMSO $(-)$, plant-derived parthenolide (PTL), and synthetic parthenolides $(-)-1,(+)-1,(-)-22$, and $(+)-22$ and stained with $\beta$ III-tubulin two days after culturing. Scale bar: $200 \mu \mathrm{m}$. (B) Quantification of axon growth of sensory DRG cultures treated with substances as described in A with concentrations as indicated. Data from treated neurons were normalized to DMSO treated controls with an average axon length of $532 \mu \mathrm{m}$ per neuron. Data represent means \pm SEM of two independent experiments. Treatment effects: $* * p \leq 0.01$; $* * * p \leq 0.001 ;{ }^{\dagger \dagger} p \leq 0.01$. Asterisks $(*)$ indicates a significant increase in axon growth while a dagger $(\dagger)$ indicates a significant decrease in axon growth.

differences seem to differentiate the stereoisomers. Furthermore, compared to dedicated anti-inflammatory agents such as glucocorticoids, the observed activity was generally mild and 


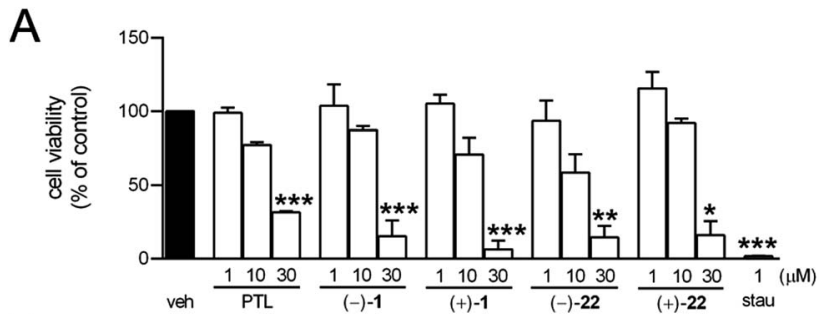

B

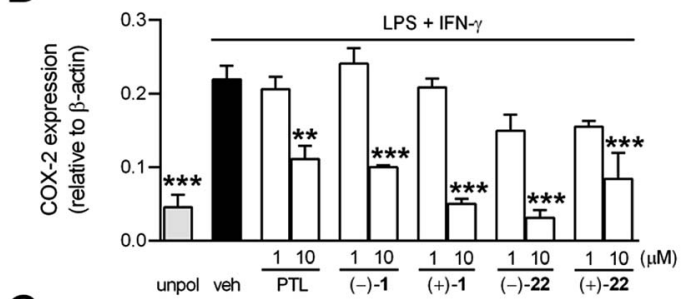

C

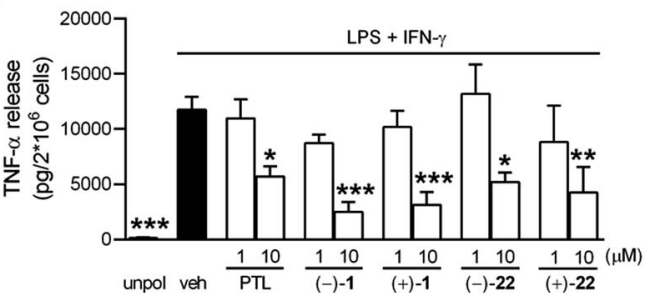

Fig. 3 Anti-inflammatory features of parthenolides in pro-inflammatory M1 macrophages. Human monocyte-derived macrophages were pre-treated with parthenolides, staurosporin (stau) or vehicle (veh, $0.3 \% \mathrm{DMSO}$ ) for $15 \mathrm{~min}$ prior to M1 macrophage polarization with LPS (100 $\mathrm{ng} \mathrm{ml}^{-1}$ ) plus IFN- $\gamma\left(20 \mathrm{ng} \mathrm{ml}^{-1}\right.$ ) for $6 \mathrm{~h}$ (B) or $48 \mathrm{~h} \mathrm{(A} \mathrm{and} \mathrm{C).} \mathrm{(A)}$ Cell viability was assessed by MTT assay. (B) Protein expression and densitometric analysis of COX-2, normalized to $\beta$-actin, compared to unpolarized (unpol). (C) TNF- $\alpha$ release in supernatants, measured by ELISA, shown as pg/ $2 \times 10^{6}$ cells. Data are means $\pm \mathrm{SEM}, n=3 .{ }^{*} p<$ $0.05, * * p<0.01, * * * p<0.001$ vs. vehicle (LPS + IFN- $\gamma$ ); one-way analysis of variance (ANOVA) with Bonferroni post hoc test.

occurred at levels that are close to the level of cytotoxicity during macrophage (M1) activation. In contrast, bioactivity on neurons is observed at the nM level, three orders of magnitude lower than the anti-inflammatory activity against macrophages at non-cytotoxic concentrations (i.e., $10 \mu \mathrm{M}$ ).

For the first time, these data confirm that the interaction of (-)-parthenolide with the structurally yet uncharacterized tubulin carboxypeptidase target is fairly specific on the molecular level-despite its covalently reactive and potentially indiscriminate $\alpha \mathrm{M} \gamma \mathrm{B}$ functional group. ${ }^{30 b}$ While further research is definitely necessary, our data may suggest that not only the presence of the epoxide in the parthenolide structure but also its positioning and hence its impact on conformation or reactivity are crucial for this mode of action. Furthermore, we found the activity mediated by TCP modulated at much lower levels of parthenolide (nM) in neuronal cells than anti-inflammatory and toxic side effects occurred in macrophages $(\mu \mathrm{M})$. While these data cannot directly be taken as a measure for therapeutic index, they do indicate that parthenolide may indeed serve as a promising template for developing non-toxic agents for neuroregeneration.

\section{Conclusions}

In order to evaluate bioactivity of parthenolide stereoisomers, we have introduced electron-rich (Z)-allylboronates (11) for the stereocontrolled synthesis of $\alpha$-(exo-)methylene $\gamma$-butyrolactones from acid labile precursors. For high levels of 1,2-asymmetric induction with $\alpha, \beta$-epoxy aldehydes, $\beta, \beta^{\prime}$ disubstitution was found to be crucial. For these substrates apparent Felkin-Anh control is operative during allylboration. These developments led to the first convergent stereoselective total synthesis of (+)- and (-)-parthenolide (1) in 16 steps from geranyl acetate (4.3\% overall yield), as well as its stereoisomers. By using these compounds the specificity of the intervention of (-)-parthenolide with microtubule detyrosination and the importance of a specific molecular interaction event when targeting this activity were validated. The synthetic methodology presented herein should facilitate the efficient synthesis of dedicated tubulin carboxypeptidase inhibiting tool compounds, and, in extension, of many other bioactive target compounds containing $\alpha \mathrm{M} \gamma \mathrm{Bs}$.

\section{Author contributions}

H.-D. A., D. F., and O. W. designed and supervised research. R. R. A. F. synthesized and characterized compounds, assisted by R. S. Cell culture and biological profiling of compounds was conducted by P. G., Z. R., and J. G. X-ray single crystal structure analysis was executed by $\mathrm{H}$. G. The manuscript was written by H.-D. A., R. R. A. F., D. F., and O. W., with contributions of all authors.

\section{Conflicts of interest}

There are no conflicts to declare.

\section{Acknowledgements}

This research was supported in part by the TMWWDG (grant no. 43-5572-321-12040-12) and the DFG (INST 275/331-1 FUGG). R. R. A. F. gratefully acknowledges a doctoral fellowship from the Fonds der Chemischen Industrie (FCI). H.-D. A. and O. W. collaborate as PIs in the CRC ChemBioSys of the DFG (SFB 1127). The work was also supported in part by the DFG grant FI $867 / 12$ (to D. F.). Mr Frédéric Gaigne is thanked for providing a sample of alcohol SI-2.

\section{Notes and references}

1 (a) H. M. R. Hoffmann and J. Rabe, Angew. Chem., Int. Ed. Engl., 1985, 24, 94-110; (b) R. R. A. Kitson, A. Millemaggi and R. J. K. Taylor, Angew. Chem., Int. Ed., 2009, 48, 94269451; (c) Ł. Albrecht, A. Albrecht and T. Janecki, in Natural Lactones and Lactams, ed. T. Janecki, John Wiley \& Sons, 2013.

2 (a) A. Ghantous, H. Gali-Muhtasib, H. Vuorela, N. A. Saliba and N. Darwiche, Drug Discovery Today, 2010, 15, 668-678;

(b) A. Janecka, A. Wyrębska, K. Gach, J. Fichna and T. Janecki, Drug Discovery Today, 2012, 17, 561-572. 
3 Variable drawings of the structure of parthenolide are reported in the literature, differing in their representation of the epoxide's stereochemistry. The molecular structure used here is stereochemically correct. A detailed description is given in the ESI. $\dagger$ For the X-ray structure determination see: A. Quick and D. Rogers, J. Chem. Soc., Perkin Trans. 2, 1976, 465-469.

4 A. M. L. Seca, A. M. S. Silva and D. C. G. A. Pinto, in Studies in Natural Products Chemistry, ed. Atta-ur-Rahman, Elsevier, 2017, vol. 52, pp. 337-372.

5 (a) S. P. Hehner, M. Heinrich, P. M. Bork, M. Vogt, F. Ratter, V. Lehmann, K. Schulze-Osthoff, W. Dröge and M. L. Lienhard Schmitz, J. Biol. Chem., 1998, 273, 12881297; (b) S. P. Hehner, T. G. Hofmann, W. Dröge and M. L. Schmitz, J. Immunol., 1999, 163, 5617-5623; (c) B. H. Kwok, B. Koh, M. I. Ndubuisi, M. Elofsson and C. M. Crews, Chem. Biol., 2001, 8, 759-766.

6 Z. Liu, S. Liu, Z. Xie, R. E. Pavlovicz, J. W. Wu, P. Chen, J. Aimiuwu, J. Pang, D. Bhasin, P. Neviani, J. R. Fuchs, C. Plass, P.-K. Li, C. Li, T. H.-M. Huang, L.-C. Wu, L. Rush, H. Wang, D. Perrotti, G. Marcucci and K. K. Chan, J. Pharmacol. Exp. Ther., 2009, 329, 505-514.

7 D. Carlisi, G. Buttitta, R. di Fiore, C. Scerri, R. Drago-Ferrante, R. Vento and G. Tesoriere, Cell Death Dis., 2016, 7, e2194.

8 (a) X. Fonrose, F. Ausseil, E. Soleilhac, V. Masson, B. David, I. Pouny, J.-C. Cintrat, B. Rousseau, C. Barette, G. Massiot and L. Lafanechère, Cancer Res., 2007, 67, 3371-3378; (b) M. Barisic, R. Silva e Sousa, S. K. Tripathy, M. M. Magiera, A. V. Zaytsev, A. L. Pereira, C. Janke, E. L. Grishchuk and H. Maiato, Science, 2015, 348, 799-803; (c) P. Gobrecht, A. Andreadaki, H. Diekmann, A. Heskamp, M. Leibinger and D. Fischer, J. Neurosci., 2016, 36, 3890-3902; (d) C. Aillaud, C. Bosc, L. Peris, A. Bosson, P. Heemeryck, J. Van Dijk, J. Le Friec, B. Boulan, F. Vossier, L. E. Sanman, S. Syed, N. Amara, Y. Couté, L. Lafanechère, E. Denarier, C. Delphin, L. Pelletier, S. Humbert, M. Bogyo, A. Andrieux, K. Rogowski and M.-J. Moutin, Science, 2017, 358, 1448-1453. 9 P. Gobrecht, M. Leibinger, A. Andreadaki and D. Fischer, Nat. Commun., 2014, 5, 4561.

10 C. Y. Chen, M. A. Caporizzo, K. Bedi, A. Vite, A. I. Bogush, P. Robison, J. G. Heffler, A. K. Salomon, N. A. Kelly, A. Babu, M. P. Morley, K. B. Margulies and B. L. Prosser, Nat. Med., 2018, 24, 1225-1233.

11 J. Nieuwenhuis, A. Adamopoulos, O. B. Bleijerveld, A. Mazouzi, E. Stickel, P. Celie, M. Altelaar, P. Knipscheer, A. Perrakis, V. A. Blomen and T. R. Brummelkamp, Science, 2017, 358, 1453-1456.

12 J. Long, S.-F. Zhang, P.-P. Wang, X.-M. Zhang, Z.-J. Yang, Q. Zhang and Y. Chen, J. Med. Chem., 2014, 57, 7098-7112.

13 Z.-J. Yang, W.-Z. Ge, Q.-Y. Li, Y. Lu, J.-M. Gong, B.-J. Kuang, X. Xi, H. Wu, Q. Zhang and Y. Chen, J. Med. Chem., 2015, 58, 7007-7020.

14 L. Li, X. Pan, B. Guan and Z. Liu, Tetrahedron, 2016, 72, 43464354.

15 W. C. Still, J. Am. Chem. Soc., 1977, 99, 4186-4187.

16 (a) P. A. Grieco and M. Nishizawa, J. Org. Chem., 1977, 42, 1717-1720; (b) H. Shibuya, K. Ohashi, K. Kawashima,
K. Hori, N. Murakami and I. Kitagawa, Chem. Lett., 1986, 15, 85-86; (c) T. Takahashi, H. Nemoto, Y. Kanda, J. Tsuji, Y. Fukazawa, T. Okajima and Y. Fujise, Tetrahedron, 1987, 43, 5499-5520; (d) S. Reddy and E. J. Corey, J. Am. Chem. Soc., 2018, 140, 16909-16913.

17 J. Long, Y.-H. Ding, P.-P. Wang, Q. Zhang and Y. Chen, J. Org. Chem., 2013, 78, 10512-10518.

18 (a) K. Foo, I. Usui, D. C. G. Götz, E. W. Werner, D. Holte and P. S. Baran, Angew. Chem., Int. Ed., 2012, 51, 11491-11495; (b) R. R. A. Freund and H.-D. Arndt, J. Org. Chem., 2016, 81, 11009-11016.

19 (a) J. A. Marshall and D. G. Cleary, J. Org. Chem., 1986, 51, 858-863; (b) I. R. Baldwin and R. J. Whitby, Chem. Commun., 2003, 2786-2787; (c) E. S. Burnell, A.-R. Irshad, J. Raftery and E. J. Thomas, Tetrahedron Lett., 2015, 56, 3255-3258.

20 T. G. Elford and D. G. Hall, Synthesis, 2010, 893-907.

21 (a) W. R. Roush, J. A. Straub and M. S. VanNieuwenhze, J. Org. Chem., 1991, 56, 1636-1648; (b) J. A. Hunt and W. R. Roush, J. Org. Chem., 1997, 62, 1112-1124; (c) A. Mengel and O. Reiser, Chem. Rev., 1999, 99, 1191-1223; (d) J. Malassis, N. Bartlett, K. Hands, M. D. Selby and B. Linclau, J. Org. Chem., 2016, 81, 3818-3837.

22 (a) V. Nyzam, C. Belaud and J. Villiéras, Tetrahedron Lett., 1993, 6899-6902; (b) J. W. J. Kennedy and D. G. Hall, J. Am. Chem. Soc., 2002, 124, 11586-11587; (c) T. G. Elford and D. G. Hall, J. Am. Chem. Soc., 2010, 132, 1488-1489; (d) B. Wen, J. K. Hexum, J. C. Widen, D. A. Harki and K. M. Brummond, Org. Lett., 2013, 15, 2644-2647; (e) J. Feng, X. Lei, R. Bao, Y. Li, C. Xiao, L. Hu and Y. Tang, Angew. Chem., Int. Ed., 2017, 56, 16323-16327.

23 K. Jiri, N. Zdenek, G. Mukund, N. Lucie, R. Ales, K. Jiri and P. Milan, Org. Lett., 2015, 17, 520-523.

24 (a) P. Knochel, J. Am. Chem. Soc., 1990, 112, 7431-7433; (b) R. W. Hoffmann, T. Sander and A. Hense, Liebigs Ann. Chem., 1993, 771-775; (c) T. Watanabe, N. Miyaura and A. Suzuki, J. Organomet. Chem., 1993, 444, C1-C3.

25 M. A. Tius and A. Fauq, J. Am. Chem. Soc., 1986, 108, 6389-6391. 26 P. Lei, Y. Ding, X. Zhang, A. Adijiang, H. Li, Y. Ling and J. An, Org. Lett., 2018, 20, 3439-3442.

27 (a) K. B. Sharpless, M. A. Umbreit, M. T. Nieh and T. C. Flood, J. Am. Chem. Soc., 1972, 94, 6538-6540; (b) K. C. Nicolaou, D. Rhoades, Y. Wang, R. Bai, E. Hamel, M. Aujay, J. Sandoval and J. Gavrilyuk, J. Am. Chem. Soc., 2017, 139, 7318-7334.

28 H. Neukirch, A. Guerriero and M. D'Ambrosio, Eur. J. Org. Chem., 2003, 3969-3975.

29 S. Raucher, K.-W. Chi, K.-J. Hwang and J. E. J. Burks, J. Org. Chem., 1986, 51, 5503-5505.

30 (a) I. Merfort, Curr. Drug Targets, 2011, 12, 1560-1573; (b) P. A. Jackson, J. C. Widen, D. A. Harki and K. M. Brummond, J. Med. Chem., 2017, 60, 839-885.

31 C. Janke, J. Cell Biol., 2014, 206, 461-472.

32 A. Ghantous, A. Sinjab, Z. Herceg and N. Darwiche, Drug Discovery Today, 2013, 18, 894-905.

33 D. Hwang, N. H. Fischer, B. C. Jang, H. Tak, J. K. Kim and W. Lee, Biochem. Biophys. Res. Commun., 1996, 226, 810-818. 